\title{
Lean Six Sigma as an enabler for Healthcare Operational Excellence in COVID-19
}

\author{
Olivia McDermott
}

College of Science and Engineering, National University of Ireland, Galway, Ireland and Jiju Antony

Operations and Logistics Group, School of Social Sciences, Heriot-Watt University, Edinburgh, Scotland, UK

\begin{abstract}
Purpose: This paper aims to present the results of a qualitative research interview study on the utilisation and importance of Lean Six Sigma methods in the Healthcare sector in COVID-19 and pandemics in general.

Design/methodology/approach: a qualitative interview approach was utilised by interviewing leading Lean Six Sigma academics and practitioners who are expert and have experience in Lean Six Sigma.

Findings: Lean Six Sigma methods are proven and can be utilised in pandemic situations to improve efficiency and resilience in the healthcare system and readiness for pandemics.

Research limitations/implications: One limitation of this research was that most of the interviewees who participated in this study come from Europe. Also, the interviews were short and at a high level. There is an opportunity for further detailed quantitative study and longitudinal case study analysis.

Originality: The paper provides an excellent resource to get an insight into the value of applying Lean Six Sigma methods in pandemic situations to aid Healthcare process improvement, operational excellence and enhance public and patient safety.
\end{abstract}

Keywords: Operational Excellence, Quality, Lean Six Sigma, Continuous Improvement, Healthcare, Pandemic

Paper type: Research article 


\section{Introduction}

COVID-19 has severely disrupted operations in health care systems. A pandemic generates demand for healthcare systems services and puts constraints on its capacity (Leite, Lindsay and Kumar, 2020). The health care community faces unprecedented how-to challenges, from rapidly scaling up disease testing to physically protecting workers with limited resources to creating physical and clinical capacity to care for highly contagious patients (Nembhard, Burns and Shortell, 2020) The ability to manage the disease until viable vaccinations are available and rolled out is partially based on the health care systems' ability to treat patients with the disease. Fortunately, the virus is showing signs of abating since the development of several approved vaccines that are being marketed. However, new strains are emerging and could result in more lockdowns (Tang, Tambyah and Hui, 2021). Globally, countries have been focused on controlling the pandemic and minimising the effects on the economy and society, but their approaches are different (Anderson et al., 2020).

Lean Six Sigma (LSS) has been applied to various health care processes to improve operations (Improta et al., 2015; Antony et al., 2018; Leite, Gruber and Hodgkinson, 2019). Lean principles are applicable in health care operations to manage demand and capacity, improve quality, improve safety, improve supplier relations and reduce costs to improve supporting processes for patient care (Hundal et al., 2021). Lean offers the opportunity to manage demand and capacity, improve quality and safety of care and reduce costs (Womack, Jones, and Roos, 1990).

This research article aims to answer the questions:

1. "What healthcare problems can Lean Six Sigma solve in COVID-19"?

2. "What LSS tools and methods can be applied within the healthcare environment to cope with COVID-19?"

3. "What are the benefits of LSS to healthcare during in COVID-19 times?"

There are valuable lessons to be learned from the utilisation of Lean Six Sigma in Healthcare daily and as a method of resilience and mitigation for future pandemics and as an enabler of operational excellence.

\section{Literature Review}

Six Sigma, coupled with Lean, can improve profits and increase customer satisfaction (Neuman and Cavanagh, 2003; Pepper and Spedding, 2010). Lean and Six Sigma was integrated by George in 2002 for improving business processes, and George has claimed that the integrated approach is superior to exploiting Lean or Six Sigma individually (George, 2002). Lean and Six-Sigma aim to improve the business's productivity and efficiency by removing waste and reducing variation, respectively (Salah, 2017; Antony et al., 2007).

Lean and Six Sigma are synergistic and complementary to each other as Lean focuses on improving information and material flow in processes and Six Sigma strives to improve the value-adding transformations which occur within the process steps by reducing variation (Antony, Snee and Hoerl, 2017; Sony, Antony and Naik, 2020).

Whilst there are not many academic papers on the role of LSS in Healthcare during COVID19, some are starting to emerge. Several articles have discussed how Lean Six Sigma can aid healthcare organisations during pandemics (Hundal et al., 2021, 2021; McDermott, Antony 
and Douglas, 2021; Salentijn, Antony and Douglas, 2021). Several authors have discussed the role of LSS principles such as utilising $5 \mathrm{~S}$, continuous flow and utilising six sigma techniques for understanding variation in test times (Balle, 2020; Laux et al, 2020; Salentijn, Antony and Douglas, 2021).

Recent studies have detailed very practical implementation and application of Lean methods during COVID-19. VelázquezPaola et al. (2020) documented the application of Lean to implement telepsychiatry during the epidemic rapidly. Sheehan, Lyons and Holt (2021) have discussed using Lean methodology to reduce personal protective equipment wastage in children undergoing congenital cardiac surgery during the COVID-19 pandemic. Following three weeks of implementing a new value stream map, the researchers reduced PPE set usage from 13 to 1 per patient resulting in annual savings of over $€ 36,000$ and reduced numbers of staff exposed to patients with an unknown SARS-CoV-2 status from 13 to 1. Pellini et al. (2021) applied lean thinking to the management of breast cancer surgery candidates in an Italian healthcare centre. Utilising Lean techniques and multivariate and regression analysis enabled the prioritised of certain high-risk groups in terms of treatment and diagnostics required. The studies, as mentioned above by VelázquezPaola et al. (2020), Sheehan, Lyons and Holt (2021), utilised many techniques and tools of LSS; VSM, 5S, Gemba, Pareto, Cause \& effect, Kanban diagrams, Multivariate and Regression Analysis to name but a few.

One of the easiest things that people can implement quickly and use easily is simple visual management systems. During COVID-19, many visual indicators have been used signs, posters, floor markers for distancing -combining visual management, go to the Gemba and 5S approaches (Balle, 2020).

Identifying waste and non-value-add touchpoints is helpful in error-proofing processes to prevent infections or minimise contact points. $5 \mathrm{~S}$ and its steps of sorting and cleaning have become more critical than ever to ensure locations of PPE, disinfectants, sterilisation agents are visible and available. Even before the pandemic hit, hospitals were faced with variability due to the absence of standardisation in many of their health care processes (VelázquezPaola et al., 2020), and this is where LSS can help by standardising processes.

In summary, Lean Six Sigma methods have a role in providing solutions and planning for contingencies when COVID-19 and other healthcare crises challenge the health system and public safety.

\section{Methodology}

The research approach used in this study is based upon content analysis, a research methodology for making valid inferences from data to their context (Klenke, 2016). Content analysis is widely adopted among scientific fields to gain knowledge, insight, and guiding practise (Wheeler, 1988; Salentijn, Antony and Douglas, 2021).

In this paper, the concepts include LSS uses, benefits and applications in COVID-19 within Healthcare settings. A Qualitative research approach with interviews was taken to focus on describing and understanding observations and opinions on the topic from a series of experts. In this research, an expert is a person with at least ten years of experience in the research discipline through research and publications or applications in a real-world setting. The participants were experienced and represented a wide range of LSS roles, organisational types and geographical areas, summarised in Table 1 below. Purposive sampling or convenience 
sampling ( $\mathrm{n}=13$ ) was utilised to collect the interviewees' in-depth qualitative semi-structured interview data (Hastings et al., 2021; Yin, 2009).

Qualitatively researching using interviews to access the potential of LSS methods and associated tools/techniques were selected as a research approach. The interviews were short and unstructured with short questions in which the interviewees were asked to answer the main question, which was "How can Lean Six Sigma enable Operational Excellence in healthcare in the era of COVID-19" and asked various sub-questions around the tools, concepts, and practices of different LSS tools and techniques that would be of benefit.

Analysis was carried out utilising NVivo, a qualitative analysis software program to aid the content analysis approach to identify the themes. Three techniques of open coding (creating a list of themes within data), axial coding (categorising or linking subcategories of themes) and selective coding (condensing of specific or excessive categories into higher-order themes) were used (Hastings et al., 2021).

Table 1: Interviewees by role, organisation type and geographical location.

\begin{tabular}{|c|c|c|c|}
\hline $\begin{array}{c}\text { Participant } \\
\text { Name }\end{array}$ & Role & $\begin{array}{c}\text { Organisation } \\
\text { type }\end{array}$ & $\begin{array}{l}\text { Geographical } \\
\text { location where } \\
\text { LSS is applied }\end{array}$ \\
\hline Participant 1 & Academic & University & $\begin{array}{c}\text { United } \\
\text { Kingdom }\end{array}$ \\
\hline Participant 2 & Consultant & Consultancy & $\begin{array}{c}\text { United } \\
\text { Kingdom }\end{array}$ \\
\hline Participant 3 & Academic & University & Ireland \\
\hline Participant 4 & Cosutant & Consultancy & Denmark \\
\hline Participant 5 & Consultant & Consultancy & USA \\
\hline Participant 6 & Consultant & Consultancy & Brazil \\
\hline Participant 7 & Aca demic & University & $\begin{array}{l}\text { The } \\
\text { Netherlands }\end{array}$ \\
\hline Participant 8 & Consultant & Consultancy & Ireland \\
\hline Participant 9 & Academic & University & Ireland \\
\hline Participant 10 & Aca demic & University & India \\
\hline Participant 11 & Consultant & Consultancy & USA \\
\hline Participant 12 & Aca demic & University & India \\
\hline Participant 13 & Process Leader & Services Org. & Ireland \\
\hline
\end{tabular}

The data was verified using the member checking technique, memoing to track the themes while coding and triangulation by the researchers(Merriam and Tisdell, 2015).

\section{The Use of LSS in the COVID-19: Key findings from the interviews}

The authors have discussed the value of using Lean Six Sigma as an enabler for operational excellence in Healthcare during COVID-19. Lean Six Sigma improvement methodologies have a role to play in current healthcare processes and practices to aid public and patient safety and improve process efficiencies. The common themes around the healthcare environment need for LSS, the benefits of LSS, and the tools of LSS in Healthcare in pandemics such as COVID-19 will be discussed. The word cloud from the research is presented in figure 1 . 


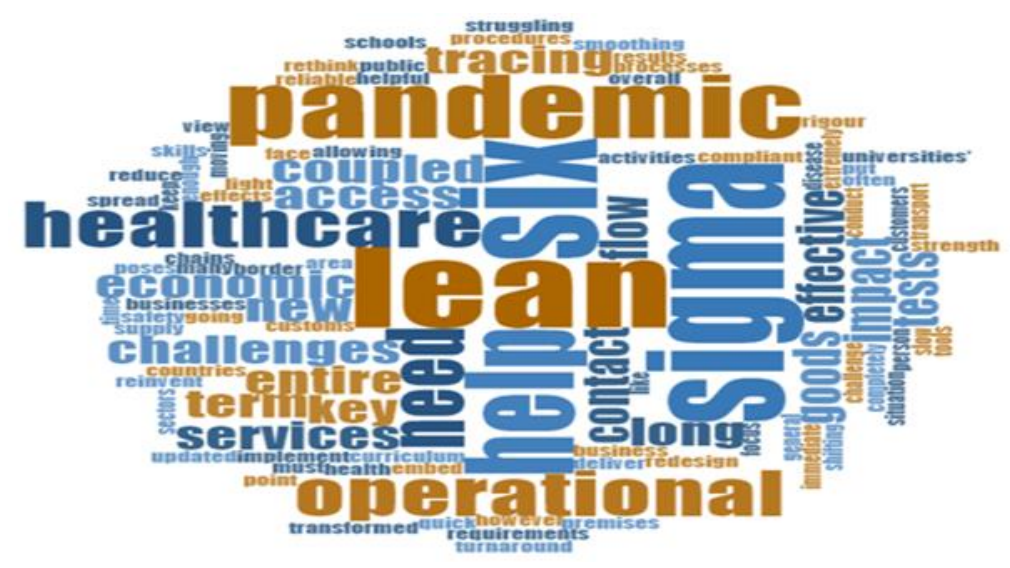

Figure 1: The Word cloud

One of the first questions asked was, "Where do you think Healthcare environments have an opportunity to utilise LSS during COVID-19?". The respondents in this study answered with some comments explicated in Table 2, and the quotes are taken "ad verbatim". This question on the potential application areas of LSS for the COVID-19 response in health care operations yielded many responses in terms of the application areas of LSS. It was felt that LSS could be applied in contact tracing, improving testing turnaround times, expediting testing processes, producing reliable results, and identifying high-risk groups. Within the vaccination process, there is an increased need for a standardised high volume process with limited waste and delays. The test time variance in terms of waiting for testing, turnaround time for results as well as variance inaccuracy of results was also an area where LSS could help. There is much-documented research on the application of LSS in Healthcare environments before COVID-19, but many studies and articles have emerged supporting the respondents' views, with many practical examples and real-world applications (Lean Enterprise Institute, 2020; Hundal et al., 2021; Pellini et al., 2021; Salentijn, Antony and Douglas, 2021).

The respondents were very positive on many areas and opportunities for LSS to be utilised in Healthcare using terms like "value add", "basic process improvement", "simple process maps", "delay reduction", "risk mitigation" to highlight how LSS could be applied in terms of service delivery and treatment.

Table 2: Excerpts of respondents on the opportunities for LSS to be utilised in Healthcare

"A value-add approach has been taken by vaccine developers and regulatory authorities with the elimination of non-value-added delays, which should shorten the development time" The success of this approach is now being seen with high vaccination rates and several available approved vaccines."

"The current reality being faced by our healthcare workers are very challenging - we can and should be using Lean and Six Sigma or basic process improvement methodologies to help Healthcare personnel to fix, improve, and transform their delivery".

"Keeping variance as low as possible and eliminating root causes for the variation is key in an integrated approach (i.e., Lean Six Sigma) on mitigating risk." 


\section{$8^{\text {th }}$ INTERNATIONAL CONFERENCE ON LEAN SIX SIGMA}

"Understanding processes through a simple process map and Value Stream mapping helps understand how nonvalue add can delay the testing processes and treatment processes."

A second question was asked on "What types of LSS tools do you think would be appropriate to help with the COVID-19 response"? The excerpts of respondents on the types of LSS tools that can be utilised are outlined in Table 3. Data analysis was considered very important and a recurring theme in terms of tracking and tracing outbreaks, identifying patterns and directing resources and supplies during outbreaks. There is evidence of data and statistical analysis in the study by Pellini et al. (2021) to predict and prioritise breast cancer treatment based on their needs and the urgency of the treatment. Risk analysis to mitigate and prevent infections and identify potential sources of risk was also deemed significant. Mapping of flow, demonstrating flow, and ensuring pull processes were considered to be very important to minimise infection and avoid backlogs in Healthcare. Fontcuberta et al. (2020) have ratified the importance of risk mitigation and flow management and given examples of hospitals in Argentina, Spain and the USA. In their examples, the critical patient flow was mapped in areas like the ICU and the flow of patients, physicians, nurses, technicians, materials and information identified to make improvements to reduce exposure, reduce and mitigate against risk and reduce the number of PPE per patient seen.

\begin{tabular}{|l|}
\hline Table 3: Excerpts of respondents on types of LSS tools for COVID-19 response \\
\hline "FMEA and Risk Assessment can help identify mission-critical areas, e.g., materials, people, \\
processes, systems, customers, components, suppliers, etc., in healthcare environments. \\
Workplaces and health care facilities can be subsequently error proofed, risks mitigated and \\
contained. Risk Analysis can help prioritise, identify, and mitigate especially against high- \\
probability and high-impact risks." \\
"LSS can be used to review historical facts and data to assess for three things for causal \\
triggers by leveraging prediction analysis tools, speeding up identification and isolation of \\
an outbreak, and finally mitigation of impact amid a pandemic." \\
"Six Sigma with its structured DMAIC approach can be utilised for projects to improve the \\
testing process, reduce testing turnaround times using simple, effective Lean tools such as \\
Value Stream Mapping. Six Sigma tools can help identify if test results are accurate utilising \\
tools such as correlation, regression analysis, hypothesis tests, etc." \\
"Healthcare is a process -right through from registration of patients to the most sophisticated \\
surgery. This means that they lend themselves to analysis and development using the core \\
concepts, tools, and applications of LSS for continuous improvement." \\
"All premises with public access need to completely redesign their access flow, to be compliant \\
with new health and safety requirements: this is where operational tools like 5S can be \\
beneficial."
\end{tabular}




\section{$8^{\text {th }}$ INTERNATIONAL CONFERENCE ON LEAN SIX SIGMA}

A third important question related to the research objective was "What do you think the benefits of LSS in Healthcare are?". Selected excerpts are outlined in Table 4.

The respondents were unanimous in their belief in the benefits of LSS, and each respondent cited several benefits of LSS. Regarding testing turnaround times and implementing more efficient contact tracing processes and procedures -there was felt to be a strong need for LSS. LSS can be applied to standardise processes, remove nonvalue add steps, gather data and, in general, improve the efficiency of the testing processes. The role of LSS in error-proofing potential sources of infection and utilising visual management to ensure zones for social distancing, signage for the requirement to sanitise and wear PPE was also felt to be very important. A recurring theme was LSS and its "Safety" benefits - 5S, VSM, process mapping, and visual management deemed integral Lean tools to minimise infection, segregate, error-proof, highlight the need for sanitising, disinfecting and wearing of PPE.

\begin{tabular}{|l|}
\hline Table 4: Excerpts of respondents on benefits of applying LSS in healthcare \\
\hline "Lean Six Sigma can help reduce turnaround time for tests and implement more effective \\
contact tracing processes." \\
"The pandemic has shown that healthcare environments have very little room for errors, and \\
they have to think critically and perform within the constraints. LSS provides tools and \\
techniques for Healthcare providers to work with, and they can then develop error-free, \\
efficient processes and services and use resources efficiently." \\
"Clear quality metrics are vital to help understand and measure the problem, help direct \\
resources, and prioritise areas. Utilising key voice of the customer (VOC) and Critical to \\
Quality (CTQ) measures helps continuously monitor the impact of problem-solving \\
iterations." \\
"Entire healthcare supply chains need to be transformed to keep the flow of PPE, drugs, \\
ventilators and provide treatment and diagnosis services going during the pandemic, in the \\
face of shortages, panic buying and even pilferage of PPE. Again, this is an area where Lean \\
Six Sigma can help."
\end{tabular}

\section{Discussions \& Implications}

All respondents emphasised the importance of Lean Six Sigma as an enabler for operational excellence in COVID-19 times. The common denominator across all responses was that the tools and techniques of LSS have a role in protecting public safety in healthcare environments in identifying and mitigating against infections.

LSS methods are thought of as a common-sense approach to ensuring public safety and improving healthcare treatments, testing, diagnosis and protecting the public. LSS as a means of providing risk assessment to minimise infection risk, provide contingency and mitigation plans for dealing with outbreaks was a common theme. Statistical and data analysis and measurement have a role in measuring, managing, and understanding infection rates and 


\section{$8^{\text {th }}$ INTERNATIONAL CONFERENCE ON LEAN SIX SIGMA}

prioritising areas of concern. Lean tools have a role in reducing nonvalue add work, errorproofing and visual management to minimise infection.

The findings from this research are a valuable source for healthcare practitioners of all levels in hospitals and healthcare settings, both inpatient and outpatient. The research demonstrates a link between how LSS will enhance patient, staff and public safety and treatment efficiency in healthcare environments. The lessons learned from applying LSS methodologies have relevance to and practical applications for healthcare settings in aiding readiness for pandemics such as COVID-19.

\section{Conclusions, limitations, and Future Work}

Lean Six Sigma can enhance patient and public safety and enable operational excellence within healthcare services. LSS can provide practitioners and academics with effective guidance to mitigate and manage everyday healthcare situations and pandemic times.

The two key findings from the study are:

1. The methodology and tools of Lean Six Sigma can help healthcare organisations treat, prevent, diagnose, and mitigate during pandemics and improve healthcare process and operational excellence.

2. Lessons learned from the COVID-19 pandemics can be utilised and integrated with Lean Six Sigma tools and techniques to aid readiness and operational resilience for these events.

Opportunities for further exploration of the use of Lean Six Sigma in a pandemic include further case studies on how hospitals coped and applied methods during COVID-19 and have lowered their infection rates. Further research via more detailed quantitative surveys on the application of LSS with a broader section of stakeholders would be valuable in informing how Lean Six Sigma was applied in COVID-19. 


\section{$8^{\text {th }}$ INTERNATIONAL CONFERENCE ON LEAN SIX SIGMA}

\section{References}

Anderson, R. M. et al. (2020) 'How will country-based mitigation measures influence the course of the COVID-19 epidemic?', The Lancet, 395(10228), pp. 931-934. doi: 10.1016/S0140-6736(20)30567-5.

Antony, J. et al. (2007) 'Can Six Sigma be the "cure” for our "ailing” NHS?', Leadership in Health Services. Edited by J. Bowerman, 20(4), pp. 242-253. doi: 10.1108/17511870710829355.

Antony, J. et al. (2018) 'Six Sigma in healthcare: a systematic review of the literature', International Journal of Quality \& Reliability Management, 35(5), pp. 1075-1092. doi: 10.1108/IJQRM-02-2017-0027.

Antony, J., Snee, R. and Hoerl, R. (2017) 'Lean Six Sigma: yesterday, today and tomorrow', International Journal of Quality \& Reliability Management, 34(7), pp. 1073-1093. doi: 10.1108/IJQRM-03-2016-0035.

Balle, Michael (2020) lean.org - Lean Enterprise Institute | Lean Production|Lean Manufacturing | LEI | Lean Services, Lean.org. Available at: https://www.lean.org/ (Accessed: 5 June 2021).

George, M.L. (2002) Lean Six Sigma: Combining Six Sigma Quality with Lean Production Speed. NY.: McGraw-Hill.

Hastings, L. et al. (2021) 'Leadership transfer in rural communities: A mixed methods investigation', Community Development, pp. 1-29.

Hundal, G. S. et al. (2021) 'Lean Six Sigma as an organizational resilience mechanism in health care during the era of COVID-19', International Journal of Lean Six Sigma, ahead-ofprint(ahead-of-print). doi: 10.1108/IJLSS-11-2020-0204.

Improta, G. et al. (2015) 'Lean Six Sigma: a new approach to the management of patients undergoing prosthetic hip replacement surgery', Journal of Evaluation in Clinical Practice, 21(4), pp. 662-672. doi: https://doi.org/10.1111/jep.12361.

Klenke, K. (2016) 'Content Analysis in Leadership Research', in Qualitative Research in the Study of Leadership. Emerald Group Publishing Limited, pp. 93-122. doi: 10.1108/978-178560-651-920152006.

Laux et al (2020) The Future Factory®: Business Transformation Training, The Future Factory®: Business Transformation Training. Available at:

https://www.thefuturefactory.com/ (Accessed: 5 June 2021).

Leite, H., Gruber, T. and Hodgkinson, I. R. (2019) 'Flattening the infection curve understanding the role of telehealth in managing COVID-19', Leadership in Health Services, 33(2), pp. 221-226. doi: 10.1108/LHS-05-2020-084.

Leite, H., Lindsay, C. and Kumar, M. (2020) 'COVID-19 outbreak: implications on healthcare operations', The TQM Journal, 33(1), pp. 247-256. doi: 10.1108/TQM-05-20200111. 
McDermott, O., Antony, J. and Douglas, J. (2021) 'Exploring the use of operational excellence methodologies in the era of COVID-19: perspectives from leading academics and practitioners', TQM journal., ahead-of-print(ahead-of-print).

Merriam, S. B. and Tisdell, E. J. (2015) Qualitative research: A guide to design and implementation. John Wiley \& Sons.

Nembhard, I. M., Burns, L. R. and Shortell, S. M. (2020) 'Responding to Covid-19: Lessons from Management Research', Nejm Catalyst Innovations in Care Delivery. doi: 10.1056/CAT.20.0111.

Neuman, R. P. and Cavanagh, R. (2003) The six sigma way: How GE, Motorola, and other top companies are honing their performance. McGraw Hill Professional: USA.

Pellini, F. et al. (2021) 'Effects of Lean Thinking and Emerging Technologies on Breast Cancer Patients' Therapeutic Process During COVID-19 Pandemic: A Case-Control Matched Study', Frontiers in Surgery, 8. doi: 10.3389/fsurg.2021.582980.

Pepper, M. P. J. and Spedding, T. A. (2010) 'The evolution of lean Six Sigma', International Journal of Quality \& Reliability Management. Edited by B. Clegg, 27(2), pp. 138-155. doi: 10.1108/02656711011014276.

Salah, S. (2017) 'Lean Six Sigma and innovation: comparison and relationship', International Journal of Business Excellence, 13(4), pp. 479-493. doi: 10.1504/IJBEX.2017.087756.

Salentijn, W., Antony, J. and Douglas, J. (2021) 'Six Sigma to distinguish patterns in COVID-19 approaches', The TQM Journal, ahead-of-print(ahead-of-print). doi: 10.1108/TQM-11-2020-0271.

Sheehan, J. R., Lyons, B. and Holt, F. (2021) 'The use of Lean Methodology to reduce personal protective equipment wastage in children undergoing congenital cardiac surgery, during the COVID-19 pandemic', Pediatric Anesthesia, 31(2), pp. 213-220. doi: https://doi.org/10.1111/pan.14102.

Sony, M., Antony, J. and Naik, S. (2020) 'How do organizations implement an effective LSS initiative? A qualitative study', Benchmarking: An International Journal, 27(5), pp. 16571681. doi: 10.1108/BIJ-10-2019-0451.

Tang, J. W., Tambyah, P. A. and Hui, D. S. (2021) 'Emergence of a new SARS-CoV-2 variant in the UK', Journal of Infection, 82(4), pp. e27-e28. doi: 10.1016/j.jinf.2020.12.024.

VelázquezPaola, P. et al. (2020) 'Rapid Implementation of Telepsychiatry in a Safety-Net Health System During Covid-19 Using Lean', NEJM Catalyst Innovations in Care Delivery. Available at: http://catalyst.nejm.org/doi/full/10.1056/CAT.20.0319 (Accessed: 5 June 2021).

Wheeler, D. R. (1988) 'CONTENT ANALYSIS: AN ANALYTICAL TECHNIQUE FOR INTERNATIONAL MARKETING RESEARCH’, International Marketing Review, 5(4), pp. 34-40. doi: 10.1108/eb008363.

Womack, J.P., Jones, D.T., and Roos, D. (1990) The Machine that Changed the World. New York: Simon and Schuster. 


\section{$8^{\text {th }}$ INTERNATIONAL CONFERENCE ON LEAN SIX SIGMA}

Yin, R. (2009), Case study research: Design and methods (4th ed.), Thousand Oaks, CA: Sage 